\title{
Burden of Elevated Body Mass Index and Its Association With Non-Communicable Diseases in Patients Presenting to an Endocrinology Clinic
}

\author{
Saima Ghaus ${ }^{1}$, Tasnim Ahsan ${ }^{2}$, Erum Sohail ${ }^{3}$, Uzma Erum ${ }^{4}$, Wasfa Aijaz ${ }^{5}$ \\ 1. Endocrinology, Medicell Institute of Diabetes, Endocrinology \& Metabolism, Karachi, PAK 2. Diabetes and \\ Endocrinology, Jinnah Postgraduate Medical Centre, Karachi, PAK 3. Endocrinology, Jinnah Postgraduate Medical \\ Centre, Karachi, PAK 4. Internal Medicine, Liaquat National Hospital, Karachi, PAK 5. Diabetes and Endocrinology, \\ Medicell Institute of Diabetes, Endocrinology \& Metabolism, Karachi, PAK
}

Corresponding author: Saima Ghaus, saima.ghaus.2021@gmail.com

\section{Abstract \\ Introduction}

In the last 45 years, the worldwide rate of obesity has risen by nearly three-folds. Globally, 650 million adults are obese and more than 1.9 billion are overweight. The estimated prevalence of overweight and obesity in Pakistan was found to be $25 \%$ and obesity prevalence alone was $10.3 \%$ using the Asian-specific body mass index (BMI) criteria. According to the World Health Organization, overweight and obesity increase the risk of non-communicable diseases (NCDs).

\section{Objectives}

The aim of this retrospective observational study was to determine the burden of elevated BMI and its association with NCDs among patients presenting to a private endocrinology clinic.

\section{Study design}

This was a retrospective observational study conducted at Medicell Institute of Diabetes, Endocrinology \& Metabolism (MIDEM), and the study duration was two years.

\section{Methodology}

Medical records of the patients who visited MIDEM from January 2017 to December 2018 were reviewed. Patients' data such as age (in years), gender, height (in cm), and weight (in kg), along with primary complaints and comorbidities were retrieved. BMI was calculated by dividing weight (in kg) by squared height (in $\mathrm{m}^{2}$ ).

Review began 02/06/2021 Review ended 02/15/2021 Published 02/21/2021

\section{(๑) Copyright 2021}

Ghaus et al. This is an open access article distributed under the terms of the Creative Commons Attribution License CC-BY 4.0., which permits unrestricted use, distribution, and reproduction in any medium, provided the original author and source are credited.

\section{Results}

A total of 613 records were reviewed. The median age and BMI were 38 years (IQR=18 - 80 years) and 28.8 $\mathrm{kg} / \mathrm{m}^{2}\left(\mathrm{IQR}=24.6-33.05 \mathrm{~kg} / \mathrm{m}^{2}\right)$, respectively. Out of 613 patients, $10.6 \%$ were overweight and $72.6 \%$ were obese. Among $510(83.2 \%)$ patients with elevated BMI $\left(\geqslant 23 \mathrm{~kg} / \mathrm{m}^{2}\right)$, the most frequent associated NCDs were dyslipidemia (39.2\%), diabetes (32.5\%), hypertension (31.4\%), thyroid disorders (28.6\%), metabolic syndrome (25\%), subfertility (14.9\%), impaired glucose tolerance (12.7\%) and autoimmune diseases (6.9\%). On age- and gender-adjusted logistic regression model, the risk of dyslipidemia, hypertension, and diabetes was significantly higher in overweight and obese patients.

\section{Conclusion}

This study demonstrated a high prevalence of obesity in patients visiting the endocrinology clinic. Obesity was identified as an independent risk factor for dyslipidemia, hypertension, and diabetes. Future studies are suggested to determine the burden of obesity and establish its association with NCDs in the general population.

Categories: Endocrinology/Diabetes/Metabolism, Family/General Practice, Epidemiology/Public Health Keywords: obesity, endocrinology, non-communicable diseases, diabetes, hypertension, dyslipidemia, thyroid disorders, autoimmune diseases, fertility, impaired glucose tolerance

\section{Introduction}

Obesity is a complex multifactorial disease, which is a substantial public health problem and has gradually worsened during the past 50 years to epidemic proportions [1]. According to the World Health Organization 
(WHO), overweight and obesity increase the risk of non-communicable diseases (NCDs). In the last 45 years, the worldwide rate of obesity has risen by nearly three-folds. Globally, 1.9 billion adults, 18 years older or above, were found as overweight and 650 million of these were obese [2]. Elevated body mass index (BMI) is a major public health issue in the first world as well as third-world countries. Around 2.8 million deaths have occurred in the world as a consequence of overweight and obesity [3]. In a study conducted in Pakistan in 2006 , the estimated prevalence of overweight and obesity was found to be $25 \%$ and obesity prevalence alone was $10.3 \%$ using the Asian-specific BMI criteria [4].

Globally, obesity is ranked as the fifth top risk factor for mortality, and it is notable that most of the world's population lives in countries where being overweight and obesity causes more mortalities than being underweight $[2,5]$. The NCDs that ensue as a consequence are associated with lesser life expectancy of nearly 5-20 years, depending on severity and other comorbid disorders [6]. Wide range of NCDs that are associated with obesity include cardiovascular diseases (CVDs), type 2 diabetes mellitus (T2DM), hypertension (HTN), dyslipidemia, respiratory problems, subfertility, erectile dysfunction, osteoarthritis, metabolic syndrome, obstructive sleep apnea (OSA), cancer, non-alcoholic fatty liver disease, and psychological issues [7].

Obesity has the potential to cause premature disability and death due as it increases the risk of NCDs. The four leading NCDs, including CVDs, T2DM, chronic respiratory diseases, and cancer, jointly contributed to $78.8 \%$ of all NCD deaths worldwide during 2016 [6,8]. Previously NCDs accounted for $52 \%$ of total mortalities in South Asia and are predicted to contribute to $72 \%$ of total deaths in this region by the end of 2030 [9]. The burden of communicable diseases and NCDs has also doubled in Pakistan as a result of epidemiological transitions, which is a great threat for healthcare systems that are not well prepared to manage the burden of NCDs [10].

In recent times, researchers have emphasized the importance of lifestyle as an essential factor for good health, as $60 \%$ of factors for quality of life and health are interrelated to lifestyle, according to the WHO. Millions of people have unhealthy lifestyles and consequently suffer from diseases, disability, and even mortality [11]. Increasing urbanization and emerging technology have led to sedentary behavior and ultimately decreased consumption of healthy food. These facts pushed us to shed the light on the current pattern of BMI in our population [12-14]. To the best of our knowledge, this is the first study from Pakistan that concurrently determined the prevalence of obesity and NCDs among adults visiting an endocrinology clinic. Even though locally generated data have documented the prevalence of obesity and overweight in Pakistan, no substantial studies are available that have investigated the association of multiple NCDs with obesity and overweight. This study was planned to investigate the burden of raised BMI and to establish its association with NCDs among patients presenting to our endocrinology clinic.

\section{Materials And Methods}

This retrospective observational study was conducted at Medicell Institute of Diabetes, Endocrinology \& Metabolism (MIDEM), which is a specialist endocrinology clinic in Karachi, Pakistan. The study was commenced after approval from the Institutional Review Board. Records of all the patients who visited the clinic for primary or follow-up consultations were reviewed. Patients of age less than 18 years were excluded from the study. Patients' records were searched from January 2017 to December 2018. Data were retrieved for patients' age (in years), gender, height (in $\mathrm{cm}$ ), weight (in kg), primary complaint, diagnosis, and any comorbidity. BMI was calculated by dividing weight (in $\mathrm{kg}$ ) by squared height (in $\mathrm{m}^{2}$ ). The Asian-specific cutoffs for BMI were used for categorizing patients as overweight $\left(23-24.9 \mathrm{~kg} / \mathrm{m}^{2}\right)$ or obese $\left(\geqslant 25 \mathrm{~kg} / \mathrm{m}^{2}\right)[15]$. Comorbidity was observed on the basis of self-reported patient's history, use of medicine for the underlying diseases, and/or confirmation of diagnosis during their follow-up visit in the clinic. Diabetes and impaired glucose tolerance were diagnosed using criteria defined by the American Diabetes Association. The criteria of the American Heart Association were used to diagnose dyslipidemia and HTN. Metabolic syndrome was identified based on the definition of the International Diabetes Federation. The American Thyroid Association guidelines were used for diagnosing thyroid disorders. Sub-fertility was diagnosed for patients who gave self-reported history, were either referred from sub-fertility clinic, or married for at least a year and had not conceived.

Data were entered into SPSS version 21 (IBM Corp., Armonk, NY, USA) for the purpose of analysis. Frequency and percentages were computed for categorical variables. Median with interquartile range (IQR) was calculated to present age and BMI after assessing the assumption of normality using the Shapiro-Wilk test. The chi-square linear-by-linear association test was applied to assess whether there was an increasing trend in disease frequency with increasing BMI. Logistic regression model was run to compute odd ratios and their $95 \%$ confidence interval to determine BMI as a predictor of NCDs. A two-tailed p-value of less than 0.05 was taken as statistically significant on logistic regression model.

\section{Results}

A total of 613 patient records were retrieved and analyzed. The median age was 38 years (IQR $=18-80$ years) and BMI was $28.8 \mathrm{~kg} / \mathrm{m}^{2}$ (IQR=24.6-33.05 kg/m²), respectively. Majority of the study participants were females $(\mathrm{n}=481$ [70.6\%]). Out of 613 patients, $103(16.8 \%), 65$ (10.6\%), and $445(72.6 \%)$ had a BMI of $\leqslant 22.9$ 


\section{Cureus}

$\mathrm{kg} / \mathrm{m}^{2}, 23-24.9 \mathrm{~kg} / \mathrm{m}^{2}$, and $\geqslant 25 \mathrm{~kg} / \mathrm{m}^{2}$, respectively. Among 510 (83.2\%) people with elevated BMI ( $\geqslant 23$ $\mathrm{kg} / \mathrm{m}^{2}$ ), the most frequent NCDs were dyslipidemia ( $\mathrm{n}=200$ [39.2\%]) followed by T2DM ( $\mathrm{n}=166$ [32.5\%]), HTN $(\mathrm{n}=160$ [31.4\%]), thyroid disorders $(\mathrm{n}=146$ [28.6\%]) with 104 (71.2\%) having hypothyroidism and the remaining 42 (28.8\%) having hyperthyroidism, metabolic syndrome ( $\mathrm{n}=127$ [25\%]), subfertility ( $\mathrm{n}=76$ [14.9\%]), impaired glucose tolerance $(n=65[12.7 \%])$, and autoimmune diseases $(n=35[6.9 \%])$.

Data analysis showed an increasing trend in disease frequency with increasing BMI (Table 1), with the result being statistically significant for dyslipidemia $(p<0.001)$, HTN $(p<0.001)$, T2DM $(p<0.001)$, impaired glucose tolerance $(\mathrm{p}<0.001)$, thyroid disorders $(\mathrm{p}=0.023)$, and metabolic syndrome $(\mathrm{p}<0.001)$. There was no statistically significant increase in autoimmune diseases $(\mathrm{p}=0.270)$ and subfertility $(\mathrm{p}=0.368)$ with increasing BMI. Age was found to be significantly associated with BMI, with a higher risk of obesity among people older than 39 years $(\mathrm{p}<0.001)$. There was no association of gender with BMI $(\mathrm{p}=0.053)$, as shown in Table 1 .

\begin{tabular}{|c|c|c|c|c|}
\hline \multirow{3}{*}{ Study variables } & \multicolumn{3}{|c|}{ Body mass index } & \multirow{3}{*}{ p-Value } \\
\hline & $\leq 22.9 \mathrm{~kg} / \mathrm{m}^{2}$ & $23-24.9 \mathrm{~kg} / \mathrm{m}^{2}$ & $\geq 25 \mathrm{~kg} / \mathrm{m}^{2}$ & \\
\hline & n (\%) & $n(\%)$ & $n(\%)$ & \\
\hline \multicolumn{5}{|l|}{ Age (in years) } \\
\hline $18-29$ & $54(52.4)$ & $15(23.1)$ & $104(23.4)$ & \multirow{5}{*}{$<0.001 \dagger$, $^{\star \star}$} \\
\hline $30-39$ & $26(25.2)$ & $18(27.7)$ & $110(24.7)$ & \\
\hline $40-49$ & $12(11.7)$ & $13(20)$ & $105(23.6)$ & \\
\hline $50-59$ & $4(3.9)$ & $13(20)$ & $82(18.4)$ & \\
\hline 60 and above & $7(6.8)$ & $6(9.2)$ & $44(9.9)$ & \\
\hline \multicolumn{5}{|l|}{ Gender } \\
\hline Male & $14(13.6)$ & $15(23.1)$ & $103(23.1)$ & \multirow{2}{*}{$0.053 \dagger$} \\
\hline Female & $89(86.4)$ & $50(76.9)$ & 342 (76.9) & \\
\hline \multicolumn{5}{|l|}{ Dyslipidemia } \\
\hline Yes & $10(9.7)$ & $20(30.8)$ & $180(40.4)$ & \multirow{2}{*}{$<0.001^{\star *}$} \\
\hline No & $93(90.3)$ & $45(69.2)$ & $265(59.6)$ & \\
\hline \multicolumn{5}{|l|}{ Hypertension } \\
\hline Yes & $6(5.8)$ & $17(26.2)$ & $143(32.1)$ & \multirow{2}{*}{$<0.001^{\star \star}$} \\
\hline No & $97(94.2)$ & $48(73.8)$ & $302(67.9)$ & \\
\hline \multicolumn{5}{|l|}{ Diabetes } \\
\hline Yes & $12(11.7)$ & $17(26.2)$ & $149(33.5)$ & \multirow{2}{*}{$<0.001^{\star \star}$} \\
\hline No & $91(88.3)$ & $48(73.8)$ & $296(66.5)$ & \\
\hline \multicolumn{5}{|c|}{ Impaired glucose tolerance } \\
\hline Yes & $0(0)$ & $7(10.8)$ & $58(13)$ & \multirow{2}{*}{$<0.001^{\star \star}$} \\
\hline No & $103(100)$ & $58(89.2)$ & $387(87)$ & \\
\hline \multicolumn{5}{|l|}{ Thyroid disorders } \\
\hline Yes & $38(36.9)$ & $24(36.9)$ & $122(27.4)$ & \multirow{2}{*}{$0.031^{*}$} \\
\hline No & $65(63.1)$ & $41(63.1)$ & $323(72.6)$ & \\
\hline \multicolumn{5}{|c|}{ Autoimmune diseases } \\
\hline Yes & $11(10.7)$ & $4(6.2)$ & $31(7)$ & \multirow{2}{*}{0.270} \\
\hline No & $92(89.3)$ & $61(93.8)$ & $414(93)$ & \\
\hline
\end{tabular}




\section{Cureus}

$\begin{array}{|lllll|}\text { Yes } & 0(0) & 7(10.8) & 120(27) & <0.001^{\star \star} \\ \text { No } & 103(100) & 58(89.2) & 325(73) & \\ \text { Subfertility } & & 67(15.1) & 0.368 \\ \text { Yes } & 21(20.4) & 9(13.8) & 378(84.9) & \\ \text { No } & 82(79.6) & 56(86.2) & \end{array}$

TABLE 1: Distribution of different non-communicable diseases among patients with body mass index of $\leq 22.9,23-24.9$, and $\geq 25 \mathrm{~kg} / \mathrm{m} 2$

†Pearson's chi-square test is reported. *Significant at $p<0.05$. ${ }^{*}$ Significant at $p<0.01$.

On logistic regression model when adjusted for age and gender, association between dyslipidemia and BMI was observed (Table 2). The risk of dyslipidemia increased by more than two-folds in overweight patients $(\mathrm{OR}=2.70$; 95\% CI: 1.12-6.52) and more than four-folds in obese patients ( $\mathrm{OR}=4.38$; 95\% CI: 2.16-8.88) in contrast to the people having BMI $\leqslant 22.9 \mathrm{~kg} / \mathrm{m}^{2}$. BMI was also found to be a predictor of HTN. The odds of HTN were higher in those who were overweight ( $\mathrm{OR}=3.60$; $95 \% \mathrm{CI}: 1.27-10.22)$ or obese (OR=5.03; 95\% CI: 2.08-12.16), in contrast to those who were of normal BMI. T2DM was also associated with BMI, with a higher risk of T2DM in patients who were obese (OR=2.15; 95\% CI: 1.04-4.45).

\begin{tabular}{|c|c|c|c|c|}
\hline Non-communicable disease & BMI of $23-24.9 \mathrm{~kg} / \mathrm{m}^{2}$, OR $(95 \% \mathrm{Cl})$ & p-Value & BMI of $\geq 25 \mathrm{~kg} / \mathrm{m}^{2}$, OR $(95 \% \mathrm{Cl})$ & p-Value \\
\hline Dyslipidemia & $2.70(1.12-6.52)$ & 0.027 & $4.38(2.16-8.88)$ & $<0.001^{\star \star}$ \\
\hline Hypertension & $3.60(1.27-10.22)$ & $0.016^{*}$ & $5.03(2.08-12.16)$ & $<0.001^{\star \star}$ \\
\hline Diabetes mellitus & $1.32(0.51-3.37)$ & 0.566 & $2.15(1.04-4.45)$ & $0.038^{\star}$ \\
\hline Thyroid disorders & $1.02(0.56-2.14)$ & 0.798 & $0.69(0.43-1.11)$ & 0.127 \\
\hline Autoimmune diseases & $0.50(0.15-1.67)$ & 0.259 & $0.56(0.26-1.21)$ & 0.139 \\
\hline Subfertility & $1.10(0.63-1.93)$ & 0.728 & $0.73(0.29-1.84)$ & 0.502 \\
\hline IGT $\dagger$ & - & - & - & - \\
\hline Metabolic syndromet & - & - & - & - \\
\hline
\end{tabular}

\section{TABLE 2: Risk of non-communicable diseases among overweight and obese}

Note: the model was adjusted for age and gender.

†OR not computed as count in reference category was zero. ${ }^{*}$ Significant at $p<0.05 .{ }^{* *}$ Significant at $p<0.01$.

IGT, impaired glucose tolerance

Logistic regression model was run to determine the risk of NCDs among male and female cohorts of overweight/obese patients in contrast to the patients with normal BMI, and the model was adjusted for age (Table 3). There was no association of BMI with thyroid disorders, autoimmune diseases, and subfertility in both genders. A significant impact of BMI was observed in increasing the risk of dyslipidemia and HTN in males. In the male cohort, the risk of dyslipidemia and HTN was 7.40 times (OR=7.40; $95 \%$ CI: 1.50-36.58) and 9.33 times (OR=9.33; 95\% CI: 1.13-77.23) higher in obese patients, respectively, in contrast to the patients with normal BMI. Among females, BMI was identified as an independent risk factor for dyslipidemia, HTN, and T2DM. In the female cohort, the odds of dyslipidemia were higher in obese females (OR=3.99; 95\% CI: 1.82-8.79) than in females with normal BMI. The risk of HTN was significantly higher in overweight (OR=4.52; 95\% CI: $1.38-14.87$ ) and obese women ( $\mathrm{OR}=4.75 ; 95 \% \mathrm{CI}: 1.75-12.91)$. The odds of T2DM were 2.50 times higher ( $\mathrm{OR}=2.5 ; 95 \% \mathrm{CI}: 1.04-6.0)$ in obese females as compared to females with normal BMI. 


\section{Cureus}

\begin{tabular}{|c|c|c|c|c|}
\hline Non-communicable disease & BMI of $23-24.9 \mathrm{~kg} / \mathrm{m}^{2}$, OR $(95 \% \mathrm{Cl})$ & p-Value & BMI of $\geq 25 \mathrm{~kg} / \mathrm{m}^{2}$, OR $(95 \% \mathrm{Cl})$ & p-Value \\
\hline \multicolumn{5}{|l|}{ Male cohort } \\
\hline Dyslipidemia & $5.79(0.89-37.53)$ & 0.066 & $7.40(1.50-36.58)$ & $0.014^{\star}$ \\
\hline Hypertension & $3.24(0.30-35.56)$ & 0.335 & $9.33(1.13-77.23)$ & $0.038^{\star}$ \\
\hline Diabetic mellitus & $0.92(0.17-5.00)$ & 0.920 & $1.42(0.36-5.60)$ & 0.614 \\
\hline Thyroid disorders & $1.80(0.13-24.15)$ & 0.657 & $2.69(0.31-23.19)$ & 0.369 \\
\hline Autoimmune diseases & $1.32(0.07-26.11)$ & 0.855 & $1.62(0.18-14.55)$ & 0.665 \\
\hline Subfertility & $1(0.06-16.26)$ & 0.99 & $0.57(0.09-3.53)$ & 0.548 \\
\hline IGT & - & - & - & - \\
\hline \multicolumn{5}{|l|}{ Female cohort } \\
\hline Dyslipidemia & $2.14(0.77-5.95)$ & 0.146 & $3.99(1.82-8.79)$ & $0.001^{\star *}$ \\
\hline Hypertension & $4.52(1.38-14.87)$ & ${ }^{*} 0.013$ & $4.75(1.75-12.91)$ & $0.002^{\star \star}$ \\
\hline Diabetic mellitus & $1.50(0.48-4.71)$ & 0.489 & $2.50(1.04-6.0)$ & $0.040^{\star}$ \\
\hline Thyroid disorders & $1.13(0.56-2.29)$ & 0.738 & $0.63(0.38-1.03)$ & 0.065 \\
\hline Autoimmune diseases & $0.44(0.11-1.72)$ & 0.238 & $0.46(0.20-1.05)$ & 0.064 \\
\hline Subfertility & $0.68(0.25-1.82)$ & 0.446 & $1.18(0.65-2.13)$ & 0.584 \\
\hline IGT† & - & - & - & - \\
\hline Metabolic syndrome & - & - & - & - \\
\hline
\end{tabular}

\section{TABLE 3: Risk of non-communicable diseases among overweight and obese for male and female}

cohort

Note: the model was adjusted for age.

†OR not computed as count in reference category was zero. *Significant at $p<0.05$. ${ }^{*}$ Significant at $p<0.01$.

IGT, impaired glucose tolerance

\section{Discussion}

This study determined the prevalence of elevated BMI $\left(\geqslant 23 \mathrm{~kg} / \mathrm{m}^{2}\right)$ and the association of BMI with the NCDs in this group. Multiple investigators from Western countries and other Asian countries have reported on the prevalence of obesity and its association with comorbidities; however, our local data are scarce [16,17]. A study from Peshawar had determined the association of NCDs with obesity, but the study only included female subjects [18].

In this study, we found a high prevalence for elevated BMI (83.2\%). A previously published study from Karachi reported 21\% study participants being obese [19]. Another study conducted in Balochistan reported $37 \%$ participants as being either overweight (15.3\%) or obese (19.5\%) [20]. A household survey reported from urban households of Karachi revealed $35.2 \%$ and $33.1 \%$ prevalence of overweight and obesity, respectively [21]. The high prevalence of obesity in our study cohort is in all probability due to the fact that these patients were attending an endocrine clinic for obesity and its related diseases.

The prevalence of overweight/obesity was not significantly different between the two genders in this study, as has also been reported by the WHO estimates of 2016 [2]. However, a Chinese study reported the prevalence of overweight to be higher in men than women, while obesity prevalence was not significantly different (27.2\% versus $25.8 \%$ ) [22]. The same finding was depicted in a Russian study that showed a considerably large difference in the prevalence of overweight between men and women ( $42.3 \%$ in men and $28.7 \%$ in females), whereas there was a small difference in obesity prevalence between males and females (27.5\% in men versus $31.4 \%$ in women) [23]. The equal occurrence of overweight and obesity in our cohort could be due to the disproportionately smaller number of male patients. 
In our study, the most prevalent NCD among people with elevated BMI was dyslipidemia (39.2\%) followed by T2DM (32.5\%), HTN (31.4\%), thyroid disorders, metabolic syndrome, subfertility, impaired glucose tolerance, and autoimmune diseases. In contrast, a Chinese study reported the highest frequency of association with HTN (46.6\%) followed by dyslipidemia (35\%) and T2DM (7.1\%) among obese participants [22]. In a study from West Texas, among patients with elevated BMI, the highest prevalence was observed for HTN (67\%) followed by dyslipidemia (59.1\%), T2DM (46.8\%), OSA (19.5\%), coronary artery disease (20.1\%), and myocardial infarction (6.3\%) [17]. Despite the difference in underlying disease prevalence and ranking, the findings of our study were similar to other studies in terms of the top three prevalent diseases, which are dyslipidemia, HTN, and T2DM. In our study, a very small number of patients spontaneously complained of symptoms suggestive of OSA, whereas the prevalence of OSA has been reported as $40 \%$ to $90 \%$ in patients with severe obesity $\left(\mathrm{BMI}>40 \mathrm{~kg} / \mathrm{m}^{2}\right.$ ) [24]. In addition to HTN, T2DM, and dyslipidemia, our study also reported a frequency of thyroid disorders, metabolic syndrome, autoimmune diseases, subfertility, and impaired glucose tolerance, but these were not significantly associated with BMI. Contrary to our finding, these diseases have been reported to be associated with BMI in other studies [25-30]. This highlights the fact that a large community-based research should be conducted to simultaneously correlate obesity with all NCDs.

Although our study included a larger sample than previously conducted local investigations and also studied obesity and NCDs concurrently, it presented the data of patients visiting an endocrinology clinic and hence the estimated prevalence of obesity and overweight is not representative of the prevalence in the general population. Since the study was retrospective in nature, the educational and socioeconomic status of study participants could not be retrieved, which are key confounders. Hence, we suggest to replicate this study in the general population incorporating all the stated limitations to accurately determine the current burden of overweight/obesity in our society and its association with NCDs.

\section{Conclusions}

This study demonstrated a higher prevalence of obesity in patients visiting a private endocrinology clinic. Obesity was identified as an independent risk factor for dyslipidemia, HTN, and diabetes. Future studies are suggested to determine the burden of obesity in the general population and establish its association with all likely NCDs.

\section{Additional Information \\ Disclosures}

Human subjects: Consent was obtained or waived by all participants in this study. Medicell Institute of Diabetes, Endocrinology \& Metabolism issued approval IRB-005/MHS/19. Animal subjects: All authors have confirmed that this study did not involve animal subjects or tissue. Conflicts of interest: In compliance with the ICMJE uniform disclosure form, all authors declare the following: Payment/services info: All authors have declared that no financial support was received from any organization for the submitted work. Financial relationships: All authors have declared that they have no financial relationships at present or within the previous three years with any organizations that might have an interest in the submitted work. Other relationships: All authors have declared that there are no other relationships or activities that could appear to have influenced the submitted work.

\section{References}

1. Panuganti KK, Nguyen M, Kshirsagar RK: Obesity. StatPearls [Internet]. StatPearls Publishing, Treasure Island, FL; 2020. https://www.ncbi.nlm.nih.gov/books/NBK459357/

2. Obesity and overweight. (2020). Accessed: December 10, 2020: https://www.who.int/news-room/factsheets/detail/obesity-and-overweight.

3. Ahirwar R, Mondal PR: Prevalence of obesity in India: a systematic review . Diabetes Metab Syndr. 2019, 13:318-21. 10.1016/j.dsx.2018.08.032

4. Jafar TH, Chaturvedi N, Pappas G: Prevalence of overweight and obesity and their association with hypertension and diabetes mellitus in an Indo-Asian population. CMAJ. 2006, 175:1071-7. 10.1503/cmaj.060464

5. Obesity Statistics. (2021). Accessed: December 10, 2020: https://easo.org/media-portal/statistics/.

6. Blüher M: Obesity: global epidemiology and pathogenesis. Nat Rev Endocrinol. 2019, 15:288-98. 10.1038/s41574-019-0176-8

7. Fruh SM: Obesity: risk factors, complications, and strategies for sustainable long-term weight management . J Am Acad Nurse Pract. 2017, 29:3-14. 10.1002/2327-6924.12510

8. Gbadamosi MA, Tlou B: Modifiable risk factors associated with non-communicable diseases among adult outpatients in Manzini, Swaziland: a cross-sectional study. BMC Public Health. 2020, 20:1-12. 10.1186/s12889-020-08816-0

9. Shrivastava U, Misra A, Mohan V, Unnikrishnan R, Bachani D: Obesity, diabetes and cardiovascular diseases in India: public health challenges. Curr Diab Rev. 2017, 13:65-80. 10.2174/1573399812666160805153328

10. Jafar TH, Haaland BA, Rahman A, et al.: Non-communicable diseases and injuries in Pakistan: strategic priorities. Lancet. 2013, 381:2281-90. 10.1016/S0140-6736(13)60646-7

11. Farhud DD: Impact of lifestyle on health. Iran J Public Health. 2015, 44:1442-4.

12. The fault in our lifestyle. (2019). Accessed: December 10, 2020: https://www.dawn.com/news/1506311. 
13. Gao Z, Lee JE: Emerging technology in promoting physical activity and health: challenges and opportunities . J Clin Med. 2019, 8:1830. 10.3390/jcm8111830

14. Is rapid urbanization making Pakistan's cities less livable? . (2020). Accessed: December 10, 2020: https://www.dw.com/en/is-rapid-urbanization-making-pakistans-cities-less-livable/a-55162735.

15. Lim JU, Lee JH, Kim JS, et al.: Comparison of World Health Organization and Asia-Pacific body mass index classifications in COPD patients. Int J Chron Obstruct Pulmon Dis. 2017, 12:2465-75. 10.2147/COPD.S141295

16. Agrawal S, Agrawal PK: Association between body mass index and prevalence of multimorbidity in low-and middle-income countries: a cross-sectional study. Int J Med Public Health. 2016, 6:73-83. 10.5530/ijmedph.2016.2.5

17. Edwards S, Bijlani S, Fairley H, Lloyd N, Rivas AM, Payne JD: Frequency and prevalence of obesity and related comorbidities in West Texas. Proc (Bayl Univ Med Cent). 2020, 33:1-4. 10.1080/08998280.2019.1668667

18. Nazli R, Akhtar T, Lutfullah G, Khan MA, Lutfullah G, Haider J: Prevalence of obesity and associated risk factor in a female population of rural Peshawar-Pakistan. Khyber Med Univ J. 2015, 7:19-24.

19. Amin F, Fatima SS, Islam N, Gilani AH: Prevalence of obesity and overweight, its clinical markers and associated factors in a high risk South-Asian population. BMC Obes. 2015, 2:16. 10.1186/s40608-015-0044-6

20. Khan I, Ul-Haq Z, Taj A, Iqbal A, Basharat S, Shah B: Prevalence and association of obesity with selfreported comorbidity: a cross-sectional study of 1321 adult participants in Lasbela, Balochistan. Biomed Res Int. 2017, 2017:1076923. 10.1155/2017/1076923

21. Ahmed A: Diabetes prevention in Pakistan: reality, challenges and outcome . Endocrinol Diabetes Res. 2017, $3: 4$.

22. Song N, Liu F, Han M, et al.: Prevalence of overweight and obesity and associated risk factors among adult residents of northwest China: a cross-sectional study. BMJ Open. 2019, 9:028131. 10.1136/bmjopen-2018028131

23. Kontsevaya A, Shalnova S, Deev A, et al.: Overweight and obesity in the Russian population: prevalence in adults and association with socioeconomic parameters and cardiovascular risk factors. Obes Facts. 2019, 12:103-14. 10.1159/000493885

24. Carter III R, Watenpaugh DE: Obesity and obstructive sleep apnea: or is it OSA and obesity? . Pathophysiology. 2008, 15:71-7. 10.1016/j.pathophys.2008.04.009

25. Song HR, Wang B, Yao Q, Li Q, Jia X: The impact of obesity on thyroid autoimmunity and dysfunction: a systematic review and meta-analysis. Front Immunol. 2019, 10:2349. 10.3389/fimmu.2019.02349

26. Fichman V, Costa RSS, Miglioli TC, Marinheiro LPF: Association of obesity and anovulatory infertility. Einstein (São Paulo). 2020, 18:O5150. 10.31744/einstein_journal/2020AO5150

27. Harpsøe MC, Basit S, Andersson M, et al.: Body mass index and risk of autoimmune diseases: a study within the Danish National Birth Cohort. Int J Epidemiol. 2014, 43:843-55. 10.1093/ije/dyu045

28. Ahmed A, Akhter J, Iqbal R, et al.: Prevalence and associations of metabolic syndrome in an urban high diabetes risk population in a low/middle-income country. Metab Syndr Relat Disord. 2020, 18:234-42. 10.1089/met.2019.0098

29. Rivers K, Hanna-Mahase C, Frankson M, Smith F, Peter S: Association between obesity and impaired glucose tolerance in new providence adolescents as demonstrated by the HbA 1c test. West Indian Med J. 2013, 62:705-10. 10.7727/wimj.2013.212

30. Al-Musa HM: Impact of obesity on serum levels of thyroid hormones among. euthyroid Saudi Adults . J Thyroid Res. 2017, 2017:5739806. 10.1155/2017/5739806 